\title{
TEKNIK PENGOPERASIAN ALAT TANGKAP PURSE SEINE PADA KMN. SAMUDERA WINDU BAROKAH JUWANA PATI JAWA TENGAH
}

\section{Operation Techniques of Purse Seine Fishing Equipment on KMN. Windu Barokah Ocean Juwana Pati Central Jawa}

\author{
Irandha C M Siahaan ${ }^{1 *}$, Rasdam ${ }^{1}$, Rudi Stiawan ${ }^{1}$, \\ ${ }^{1}$ Program Studi Teknik Penangkapan Ikan Politeknik Kelautan Dan Perikanan Kupang \\ *Corresponding author: irandha47@gmail.com
}

\begin{abstract}
ABSTRAK
Purse seine adalah alat tangkap yang efektif untuk menangkap ikan-ikan pelagis yang bersifat bergerombol dan hidup di dekat permukaan air. Alat tangkap ini bersifat aktif karena dalam pengoperasiannya yaitu dengan cara menghalangi, mengurung serta mempersempit ruang gerak dari ikan sehingga ikan tidak dapat melarikan diri. Praktik akhir diadakan pada bulan November 2020 hingga bulan mei 2021. Metode pengumpulan data yang digunakan adalah observasi partisipan. Dari hasil pengamatan diketahui bahwa teknik pengoperasian alat tangkap yaitu sama seperti purse seine light fishing pada umumnya yang menggunakan bantuan cahaya lampu untuk mengumpulkan gerombolan ikan selanjutnya ikan dialihkan pada lampu bangkra, lalu kapal bergerak melingkari bangkra sambil menurunkan alat tangkap kemudian diikuti dengan pengerutan bagian bawah jaring sehingga ikan terkurung didalamnya. Jenis ikan hasil tangkapan pada KMN. Samudera Windu Barokah umumnya berupa ikan-ikan kecil seperti Layang, Lemuru, Kemung, dan Selar. Sedangkan untuk jenis ikan-ikan besar seperti Tongkol, Layur, Barakuda, Kuwe serta Bawal.
\end{abstract}

Kata kunci: Purse Seine, Alat Tangkap. Hasil Tangkapan.

\section{ABSTRACT}

Purse seine is an effective fishing tool for catching pelagic fish that are in groups and live near the surface of the water. This fishing gear is active because in its operation it is by blocking, confining and narrowing the movement space of the fish so that the fish cannot escape. The final practice was held from November 2020 to May 2021. The data collection method used was participant observation. From the observations, it is known that the fishing gear operating technique is the same as purse seine light fishing in general, which uses the help of a lamp to collect schools of fish, then the fish are transferred to the bangkra lamp, then the ship moves around the bangkra while lowering the fishing gear followed by shrinking the bottom of the net. so the fish are trapped in it. Types of fish caught in KMN. Ocean Windu Barokah generally consists of small fish such as Layang, Lemuru, Kemung, and Selar. As for the types of large fish such as Tongkol, Layur, Barracuda, Kuwe and Bawal.

Keywords: Purse Seine, Fishing Equipment. Catch.

\section{PENDAHULUAN}

ndonesia mempunyai perairan laut seluas 5,8 juta $\mathrm{km}^{2}$ yang terdiri dari perairan kepulauan dan teritorial seluas 3,1 juta $\mathrm{km}^{2} \quad$ serta perairan Zona Ekonomi Eksklusif Indonesia (ZEEI) seluas 2,7 juta $\mathrm{km}^{2}$ dengan potensi lestari sumber daya ikan sebesar 6,4 juta ton/tahun. 
Sumber daya ikan ini pada kenyataannya tidak tersebar merata di seluruh perairan Indonesia. Hal tersebut antara lain dikarenakan perbedaan kondisi lingkungan perairan dan perbedaan tingkat pemanfaatan sumber daya ikan di beberapa wilayah. Indonesia adalah negara yang mempunyai wilayah perairan laut dan perairan darat yang sangat luas dibandingkan negara ASEAN lainnya. Sumberdaya alam ini salah satunya menghasilkan ikan dan hasil perikanan lainnya. Oleh karenanya, akhir - akhir ini pemerintah sangat mengintensifkan usaha penangkapan dan budidaya ikan dalam upaya mendapatkan pemasukan devisa yang lebih besar. Namun, usaha tersebut akan menjadi tidak berguna jika tidak dibarengi dengan peningkatan pengetahuan tentang penanganan ikan setelah penangkapan (Junianto, 2003).

Munculnya alat tangkap purse seine menjawab semua permasalahan tentang penangkapan ikan yang aman karena dalam pengoperasiannya tidak mengganggu atau merusak ekosistem yang ada didalam perairan. Purse seine adalah alat tangkap yang efektif untuk menangkap ikan-ikan pelagis yang bersifat bergerombol dan hidup di dekat permukaan air. Alat tangkap ini bersifat aktif karena dalam pengoperasiannya yaitu dengan cara menghalangi, mengurung serta mempersempit ruang gerak dari ikan sehingga ikan tidak dapat melarikan diri (Subani dan Barus 1989).

Pengoperasian alat tangkap purse seine dilakukan dengan 2 (dua) tahap yaitu Setting dan Hauling. Keberhasilan proses Setting dan Hauling sangat dipengaruhi oleh beberapa faktor seperti kecepatan melingkar jaring, kecepatan tenggelamnya pemberat serta kecepatan penarikan tali kolor, dimana faktor-faktor ini dapat mempengaruhi tingkat efisiensi serta keberhasilan pengoperasian alat tangkap purse seine. Untuk itu agar pengoperasian dapat berjalan secara efisien maka dalam pengelolaannya harus dibutuhkan Sumber Daya Manusia (SDM) yang terampil dan profesional.

\section{METODE PENELITIAN}

Pengamatan dilaksanakan pada tanggal 16 November 2020 sampai tanggal 16 Mei 2020 yang bertempat di Pelabuhan Perikanan Pantai Bajomulyo, Kecamatan Juwana, Kabupaten Pati, Provinsi Jawa Tengah.

\section{Prosedur Praktik}

Metode yang digunakan adalah metode diskriptif, yaitu metode dalam meneliti status sekelompok manusia, suatu objek, suatu set kondisi, suatu sistem pemikiran ataupun suatu kelas peristiwa pada masa sekarang (Nazir, 2002).

\section{Pengamatan Teknik Pengoperasian}

Penulis mengkaji beberapa hal terkait pengoperasian alat tangkap mulai dari penurunan jaring hingga pengangkatan jaring. Setelah itu penulis juga mencatat data terkait kondisi sekitar pengoperasian alat tangkap dan lama waktu pengoperasian alat tangkap. Penulis mencatat data berupa titik koordinat operasi penangkapan per setting alat tangkap dan mencatat nama lokasi sebagai daerah pengoperasian purse seine

\section{Pengamatan Hasil Tangkapan}

Penulis mendata hasil tangkapan pada setiap setting pengoperasian alat tangkap. Adapun data yang diperoleh, yaitu jumlah ( produksi hasil tangkapan ikan dan spesies hasil tangkapan ikan setiap operasi penangkapan purse seine ).

\section{Analisis Data}

Dalam Kerja Praktik Akhir, penulis menggunakan teknik pengumpulan data Observasi partisipan. Sukandarrumidi (2004), menjelaskan pengertian observasi adalah pengamatan dan pencatatan suatu objek dengan sistematika fenomena yang diamati. Sehingga pada observer terlibat langsung 
dan ikut serta dalam kegiatan-kegiatan yang dilakukan oleh subjek yang diamati. Dalam teknik observasi terdapat 2 hal yang harus diperhatikan, pengamatan observer adalah benar, hal ini dapat dilakukan apabila observer menguasai bidang ilmunya dan ingatan observer dapat dipertanggung jawabkan, hal ini dapat ditingkatkan apabila observer dapat segera mencatat apa yang telah berhasil diamati dan dibantu dengan peralatan elektronik atau alat tulis. Sarana yang akan digunakan adalah catatan berkala dan check list.

\section{HASIL DAN PEMBAHASAN \\ Teknik Pengoperasian Alat Tangkap}

Kapal purse seine yang penulis ikuti beroperasi pada malam dan dini hari sehingga menggunakan teknik light fishing atau yang penangkapan ikan menggunakan lampu atau cahaya untuk menarik perhatian ikan. Dalam pengoperasian purse seine terdapat beberapa tahap antara lain, persiapan pengoperasian dilakukan untuk memperlancar kegiatan operasi penangkapan agar berjalan efektif dan efisien. Adapun persiapan yang di lakukan pada KMN. Samudera Windu Barokah ini terdiri dari persiapan di darat serta persiapan di laut.

Persiapan yang dilakukan didarat antara lain seperti pengecekan kelengkapan alat yang digunakan untuk pengoperasian alat tangkap dan alat-alat untuk memperbaiki mesin dan alat tangkap, pengecekan mesin, perbekalan berupa bahan makanan dan minuman serta obat-obatan, BBM untuk seluruh mesin yang ada dikapal, kelengkapan surat-surat kapal, air tawar, serta meletakan sesajen di haluan dan kamar mesin. Setelah semuanya telah siap maka kapal siap menuju daerah penangkapan. Dari fishing base ke fishing ground memerlukan waktu 2 hari untuk sampai sehingga ada persiapan-persiapan yang dilakukan di laut seperti penataan alat tangkap agar pada saat setting alat tangkap dapat beroperasi dengan baik, penataan nampan untuk mendinginkan ikan, penataan ruang $\mathrm{ABK}$, penataan tiangtiang atau power block.

\section{Penentuan Lokasi Fishing Ground}

Berdasarkan surat ijin operasi penangkapan pada KMN. Samudera Windu Barokah mendapat daerah penangkapan (fhising ground) pada perairan Selat Makasar yang masuk dalam Wilaya Pengelolaan Perikanan (WPP) 713 yang meliputi perairan Selat Makasar,Teluk Bone,Laut Flores dan Laut Bali. Penentuan fishing ground juga bisa dilakukan bergantung pada keputusan tekong (Nakhoda). Keputusan yang diambil berdasarkan pengalaman melaut pada trip-trip sebelumnya atau informasi dari kapal lain yang mendapat banyak tangkapan pada suatu perairan. Jika pada fishing ground yang ditentukan mendapat banyak hasil tangkapan, maka kapal akan tetap berada pada daerah tersebut hingga hasil tangkapan dirasa sedikit barulah kapal berpindah ke daerah penangkapan yang baru. 


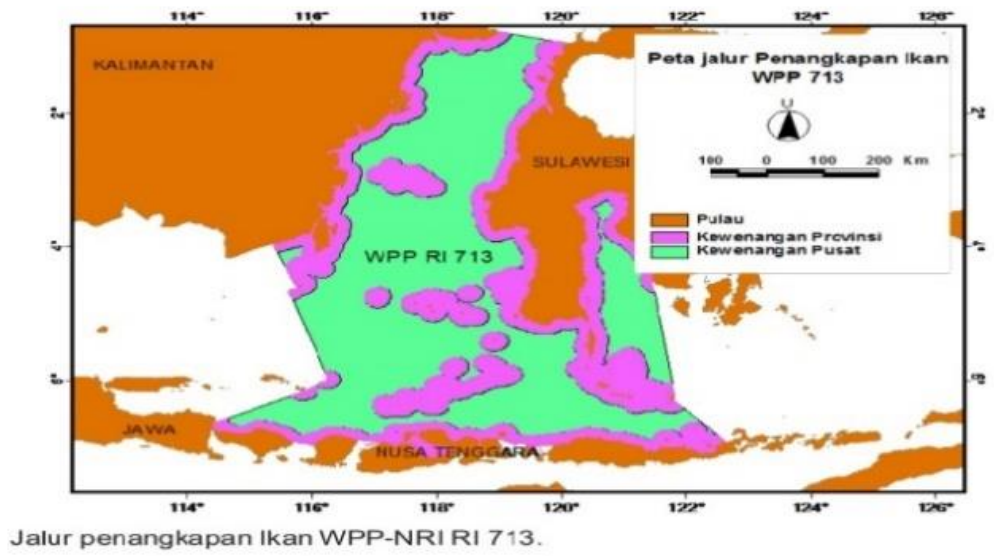

Gambar 1. Lokasi pengamatan

Pengumpulan Gerombolan Ikan

Teknik pengumpulan gerombolan ikan yang dilakukan menggunakan alat bantu penangkapan berupa rumpon mini serta cahaya lampu sebagai penarik perhatian ikan. Lampu yang dipasang di atas kapal memiliki 3 jenis berbeda, masing-masing dengan fungsinya terhadap rambat cahaya didalam air. Lampu luna maya memberikan sebaran cahaya yang luas ke sekitar kapal, lampu corong memberikan sebaran cahaya yang dalam ke bawah kapal, sedangkan lampu galaxy memberikan sebaran cahaya yang lebih sempit dan tidak telalu dalam agar ikan naik ke kepermukaan. Lampu-lampu yang digunakan dapat dilihat pada Tabel 1.

Tabel 1. Penggunaan Lampu di Atas Kapal

\begin{tabular}{|c|c|c|c|c|c|c|c|}
\hline \multirow{2}{*}{$\begin{array}{l}\text { Jenis } \\
\text { Lampu }\end{array}$} & \multirow{2}{*}{ Letak } & \multirow{2}{*}{ Warna } & \multirow{2}{*}{$\begin{array}{l}\text { Daya } \\
\text { Lampu }\end{array}$} & \multicolumn{3}{|c|}{ Posisi } & \multirow{2}{*}{ Jumlah } \\
\hline & & & & Kiri & Kanan & Belakang & \\
\hline $\begin{array}{l}\text { Luna } \\
\text { maya }\end{array}$ & Atas & Putih & $1500 \mathrm{~W}$ & 7 & 7 & 2 & 16 \\
\hline Corong & Tengah & Hijau & $1500 \mathrm{~W}$ & 3 & 3 & 2 & 8 \\
\hline \multirow[t]{3}{*}{ Galaxy } & Bawah & Putih & $400 \mathrm{~W}$ & 11 & 11 & 6 & 30 \\
\hline & & Kuning & $250 \mathrm{~W}$ & & & 2 & 2 \\
\hline & Haluan & Putih & $400 \mathrm{~W}$ & 1 & 1 & & 2 \\
\hline & & & Total & & & & 58 \\
\hline
\end{tabular}

\section{Penurunan Alat tangkap (Setting)}

Penurunan alat tangkap dilakukan apabila keadaan arus dan angin baik dan ikan sudah banyak yang bermain disekitaran kapal. Ketika ikan sudah banyak di sekitaran kapal maka lampu bangkra diturunkan. Kemudian 2 orang menjaga lampu bangkra dan membawa lampu bangkra menjauhi kapal sehingga ikan akan terfokus hanya pada lampu bangkra tersebut. Kemudian kapal terus mengitari bangkra sambil memperhatikan arah angin dan arus yang sesuai untuk menurunkan alat tangkap. Perhitungan arah angin dan arus ini sangat berpengaruh terhadap sempurnanya bukaan jaring dan posisi kapal pada saat hauling nantinya. Arah angin dapat diketahui dengan arah kibaran bendera yang dipasang pada tiang haluan sedangkan arah arus diketahui dengan hanyutnya atraktor rumpon. Posisi kapal pada awal setting yaitu berada dibawah angin serta arus tidak mengarah bagian bawah kapal. Berikut adalah gambaran posisi kapal pada saat setting. 


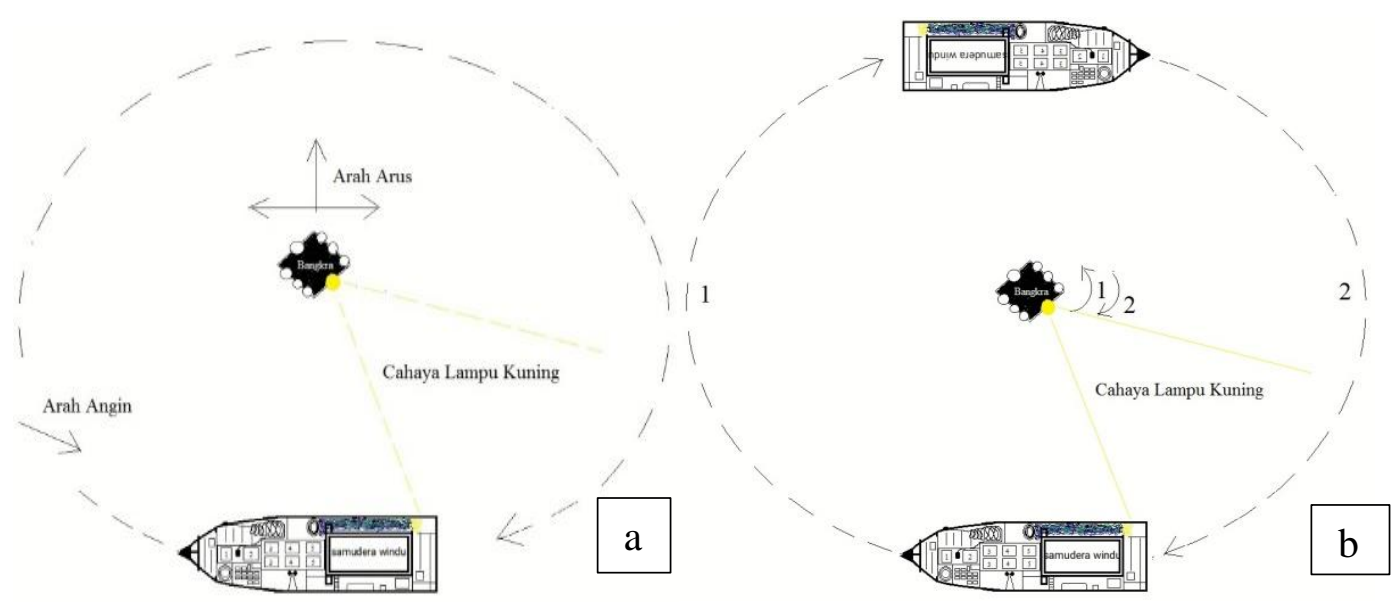

Gambar 2. (a) Posisi Awal Kapal Saat Setting (b) Arah Lampu Bangkra Saat Setting

Penurunan alat tangkap dilakukan

secara bertahap dimulai dengan penurunan pemberat (3 $\mathrm{ABK})$, jaring (1 $\mathrm{ABK})$, pelampung $(1 \mathrm{ABK})$, diikuti dengan seorang ABK yang telah dilengkapi pelampung melompat dari buritan sambil memegang lampu tanda. Setelah setengah alat tangkap diturunkan maka roller tancap pun dipasang pada bagian tengah lambung kanan kapal. Seorang ABK terus mengulurkan tali kolor melewati besi yang ditancapkan pada haluan kanan dengan menjaganya agar tetap kencang. Kapal terus melingkari bangkra sambil menurunkan alat tangkap hingga tiba pada lampu tanda.

Pada saat alat tangkap diturunkan, hal yang juga perlu diperhatikan adalah arah lampu bangkra. Lampu bangkra berwarna kuning selalu diarahkan pada bagian perairan yang belum mendapat lingkaran jaring. Hal ini bertujuan agar menjaga area renang ikan tetap berada didalam lingkaran jaring karena fungsi dari lampu ini yaitu menutup area renang ikan. Setelah setting dilakukan, bangkra ditarik ke bagian pelampung terjauh dan lampu kuning terus diarahkan ke lambung kanan kapal (tempat menutupnya bagian bawah jaring) untuk mencegah ikan kabur sebelum cincin dikerutkan. Proses penurunan alat tangkap/setting memerlukan waktu sekitar 10-15 menit.

\section{Penarikan Alat Tangkap (Hauling)}

Penarikan dimulai dengan penaikan pelampung tanda yang tersambung pada tali selambar. Kemudian tali selambar ditarik menggunakan gardan hingga pelampung naik keatas kapal. Ujung tali kolor bagian depan yang diikatkan pada selambar dibuka dan dipasang melalui roller tancap. Tali jambang segera ditarik untuk menaikan setiap sudut bagian bawah alat tangkap. Dalam penarikan alat tangkap sampai ujung kantong jaring memerlukan waktu sekitar 45 menit. 


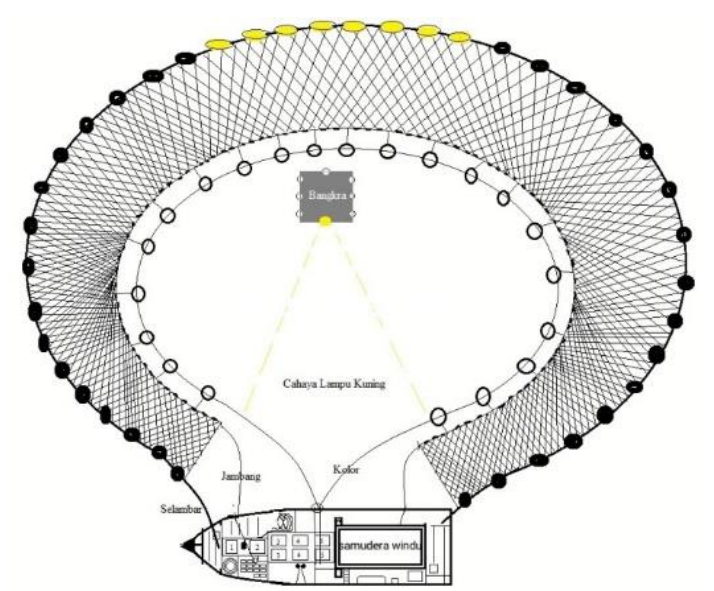

Gambar 3. Posisi Awal Penarikan Alat Tangkap

Dalam penarikan tali jambang, dilakukan juga penarikan ris samping untuk menaikan setiap sisi jaring. Pelampung dan sayap jaring ditariksedikitdemi

sedikit dengan menjaga agar alat tangkap tetap terbuka secara sempurna. Penarikan dilakukan dengan cepat dan cermat agar tali kolor dan jaring tetap kencang guna menghindari tersangkutnya jaring pada baling-baling kapal karena terbawa arus. Sistem penarikan tali kolor yaitu dengan menggunakan alat bantu berupa gardan dan roller. Gardan yang digunakan berjumlah 2 buah terletak pada sisi kiri dan kanan kapal. Untuk bahan dasar terbuat dari kayu, hal ini disesuaikan dengan jenis bahan tali kolor yang berupa polyethylene. Sedangkan penggunaan roller berjumlah 4 buah yang dipasang pada lambung kanan (roller tancap) dan dek kiri kapal (roller tetap).

\section{Jenis Ikan Tangkapan}

Jenis tangkapan utama merupakan jenis ikan yang dalam mencari makan tertarik pada cahaya lampu serta membentuk suatu gerombolan sehingga menjadi target utama penangkapan dengan alat tangkap purse seine. Sedangkan untuk jenis tangkapan sampingan adalah jenis ikan predator yang keberadaannya untuk memangsa ikan-ikan kecil. Presentase jumlah hasil tangkapan utama dan tamgkapan sampingan pada KMN. Samudera Windu Barokah dapat dilihat sebagai berikut:

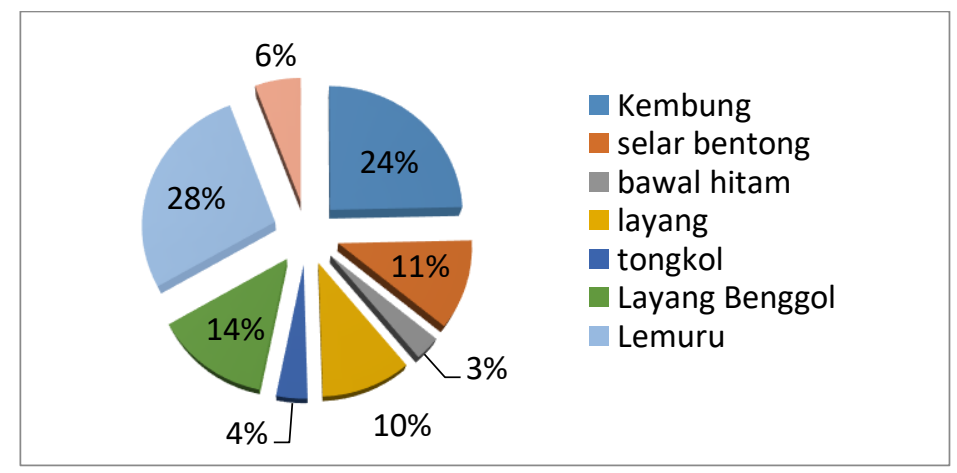

Gambar 4. Presentase Hasil Tangkapan

Data diatas menunjukan bahwa benar hasil tangkapan dengan alat tangkap purse seine lebih didominasi oleh ikan-ikan pelagis yang membentuk suatu gerombolan. Ikan pelagis yang banyak tertangkap yaitu berturut-turut Lemuru 28\%, Kembung 24\%, Layang Benggol 14\%, Selar Bentong $11 \%$, 
Layang 10\%, Tongkol 4\%, dan Bawal Hitam 3\% dari jumlah keseluruhan ikan hasil tangkapan $91403 \mathrm{Kg}$. Sedangkan untuk ikan hasil tangkapan sampingan hanya $6 \%$ yang sebagian besar merupakan ikan-ikan pemangsa seperti ikan Kuwe, Layur dan Barakuda. Hal ini sesuai dengan pendapat Tani (2020) bahwa ikan yang menjadi tujuan penangkapan dari pukat cincin adalah ikan-ikan pelagic shoaling spesies, yang berarti ikan-ikan tersebut haruslah membentuk shoal (gerombolan) antara lain Layang, Kembung, Selar, Tongkol, Cakalang, Sardine dan jenis ikan pelagis lainnya.

Jumlah hasil tangkapan desember 2020 terKomposisi sebanyak $22.761 \mathrm{~kg}$ yang terdiri dari ikan Lemuru $5.100 \mathrm{~kg}$, Layang Benggol $4.000 \mathrm{~kg}$, Layang 2.000 $\mathrm{kg}$, Tongkol $2.200 \mathrm{Kg}$, Selar Bentong $3.000 \mathrm{Kg}$, Kembung 5.500 Kg, Kuro 61 $\mathrm{Kg}$, Talang $900 \mathrm{Kg}$.

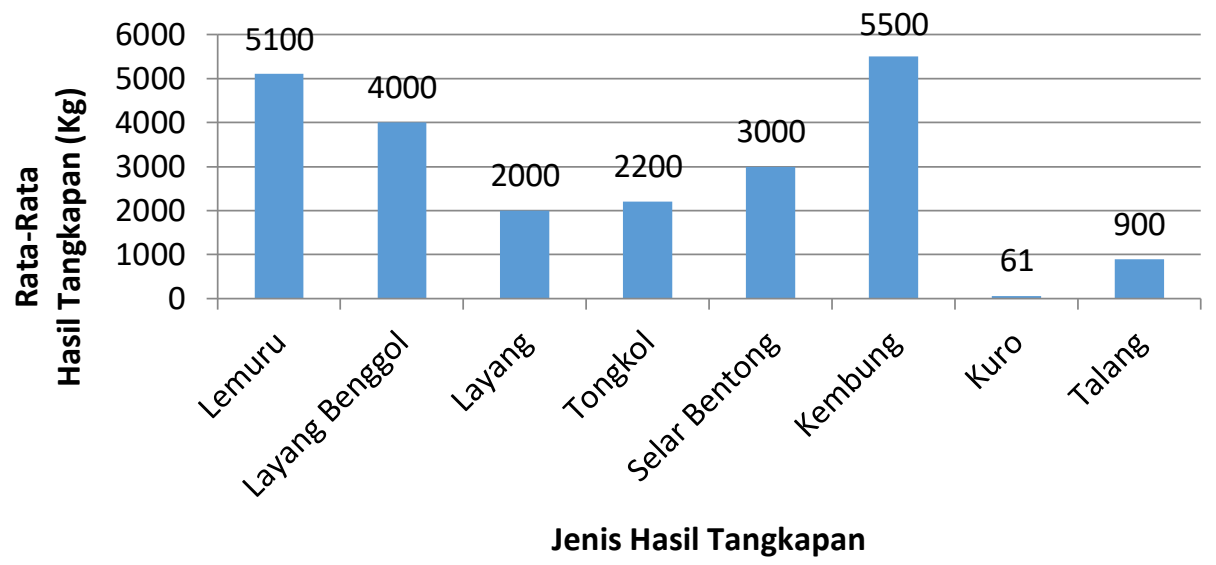

Gambar 5. Hasil Tangkapan Bulan Desember

Ikan hasil tangkapan yang paling banyak tertangkap pada bulan Desember 2020 adalah ikan Kembung. Untuk lebih jelas dapat dilihat pada gambar 5. Jumlah hasil tangkapan pada bulan Januari 2021 terKomposisi sebanyak $13.910 \mathrm{~kg}$ yang terdiri dari ikan Lemuru $4.500 \mathrm{~kg}$, Layang Benggol $2.500 \mathrm{~kg}$, Layang 1.000, Tongkol $1.100 \mathrm{~kg}$, Selar Bentong 1.000 $\mathrm{kg}$, Kembung 3.500 kg, Juwi 60 kg, Selar Kuning $250 \mathrm{Kg}$.

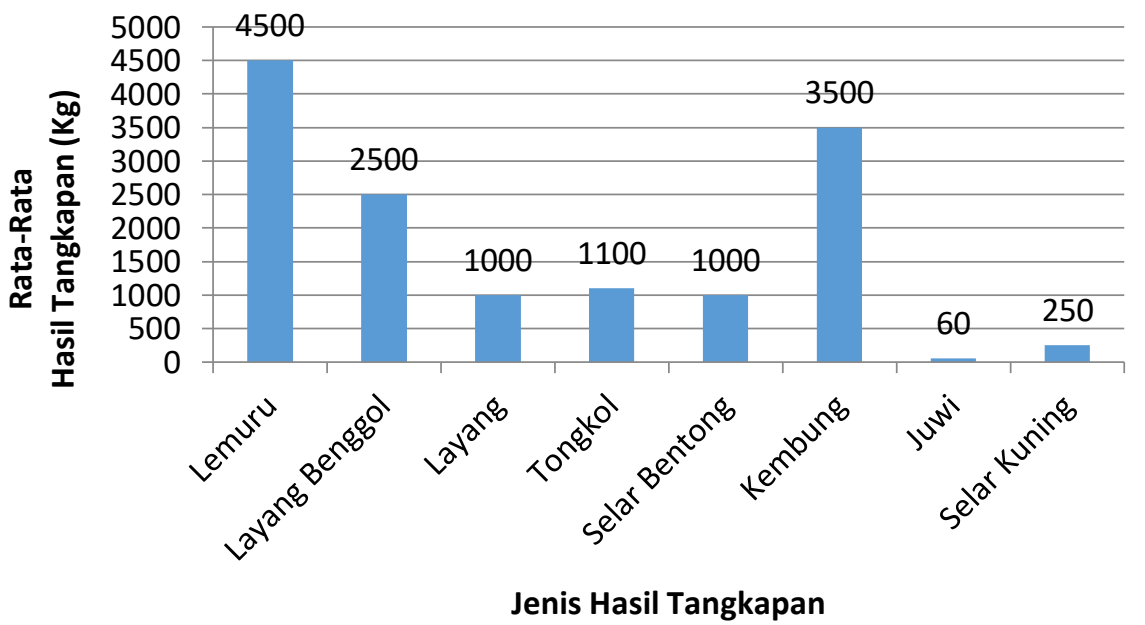

Gambar 6. Hasil Tangkapan Bulan Januari 
Jumlah hasil tangkapan bulan Febuari 2021 terkomposisi sebanyak $14.277 \mathrm{~kg}$ yang terdiri dari ikan Lemuru $4.000 \mathrm{~kg}$, Layang Benggol $1100 \mathrm{~kg}$,
Layang $1.500 \mathrm{~kg}$, Selar Bentong 2.000 $\mathrm{Kg}$, Kembung 4.500 Kg, Selar Tetengkek $350 \mathrm{Kg}$, Kurisi 477 Kg, Selar Kuning 350 $\mathrm{Kg}$.

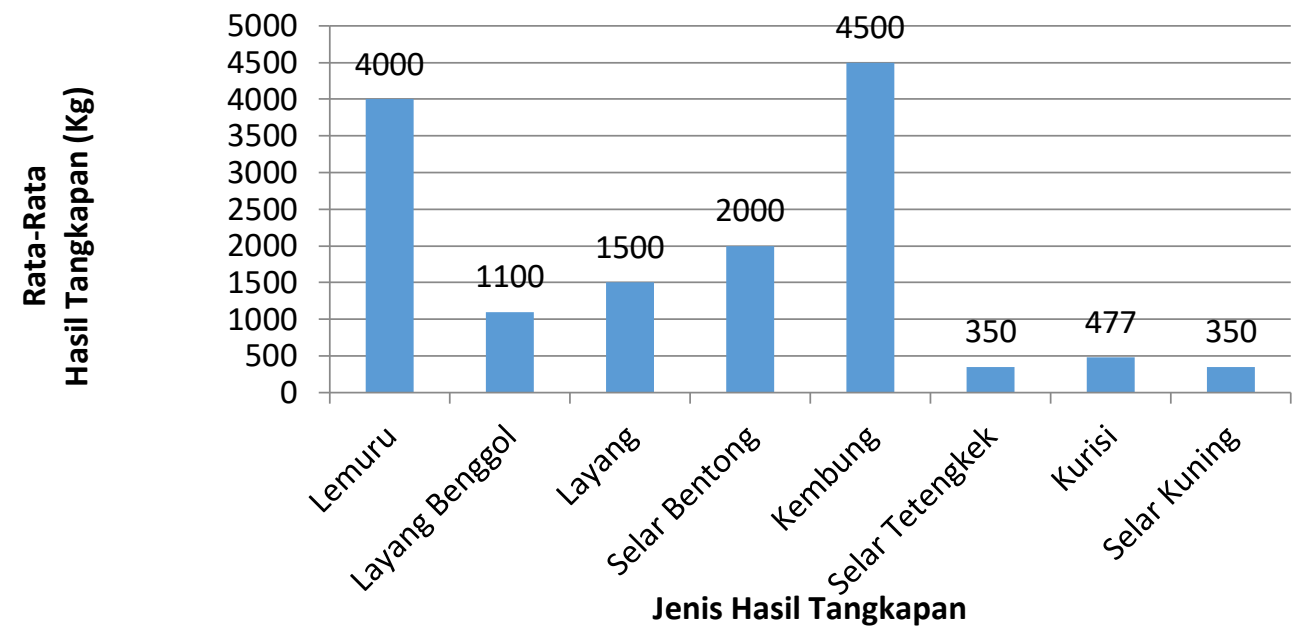

Gambar 7. Hasil tangkapan Bulan Februari

Jumlah hasil tangkapan bulan Maret 2021 terKomposisi sebanyak $16.390 \mathrm{~kg}$ yang terdiri dari ikan Lemuru $5.200 \mathrm{~kg}$, Layang Benggol $900 \mathrm{~kg}$,
Layang $3.000 \mathrm{~kg}$, Selar Bentong 2.100 $\mathrm{kg}$, Kembung $4500 \mathrm{~kg}$, Layur $60 \mathrm{Kg}$, Selar Tenggkek $450 \mathrm{Kg}$, Kuwe $180 \mathrm{Kg}$.

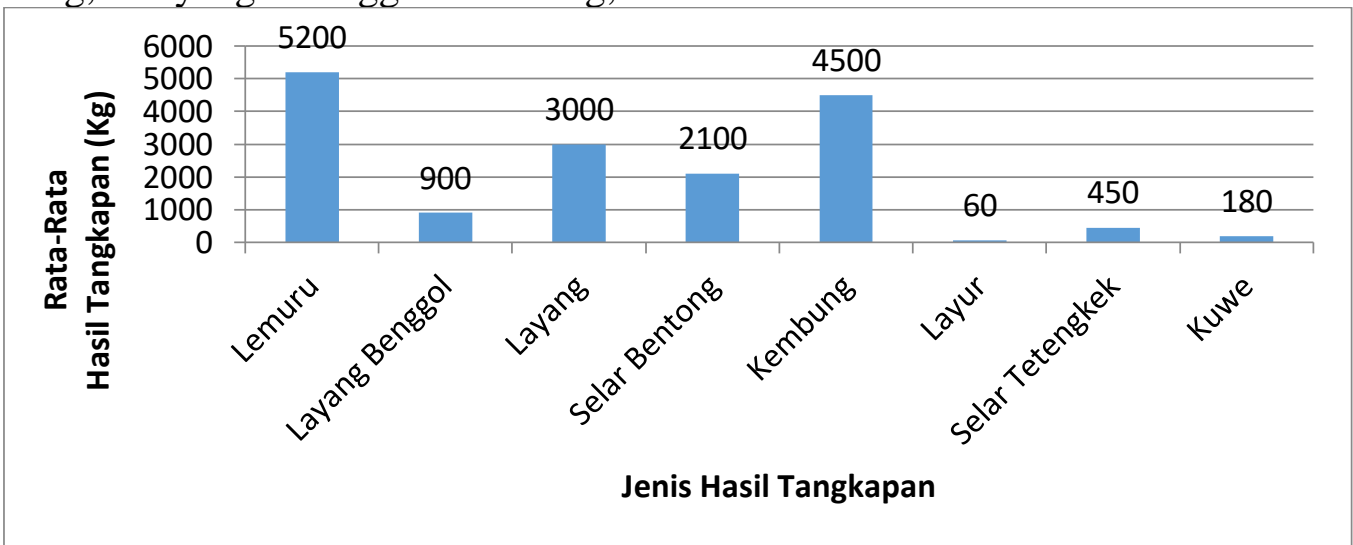

Gambar 8. Hasil Tangkapan Bulan Maret

Jumlah hasil tangkapan bulan April 2021 terKomposisi sebanyak $20.350 \mathrm{~kg}$ yang terdiri dari ikan Lemuru $6.300 \mathrm{~kg}$, Layang Benggol $3.500 \mathrm{~kg}$,
Layang $2.000 \mathrm{~kg}$, Selar Bentong 2.100 $\mathrm{kg}$, Kembung $4.500 \mathrm{~kg}$, Selar Tetengkek $600 \mathrm{~kg}$, Barakuda $360 \mathrm{~kg}$ dan Talang $1.000 \mathrm{~kg}$. 


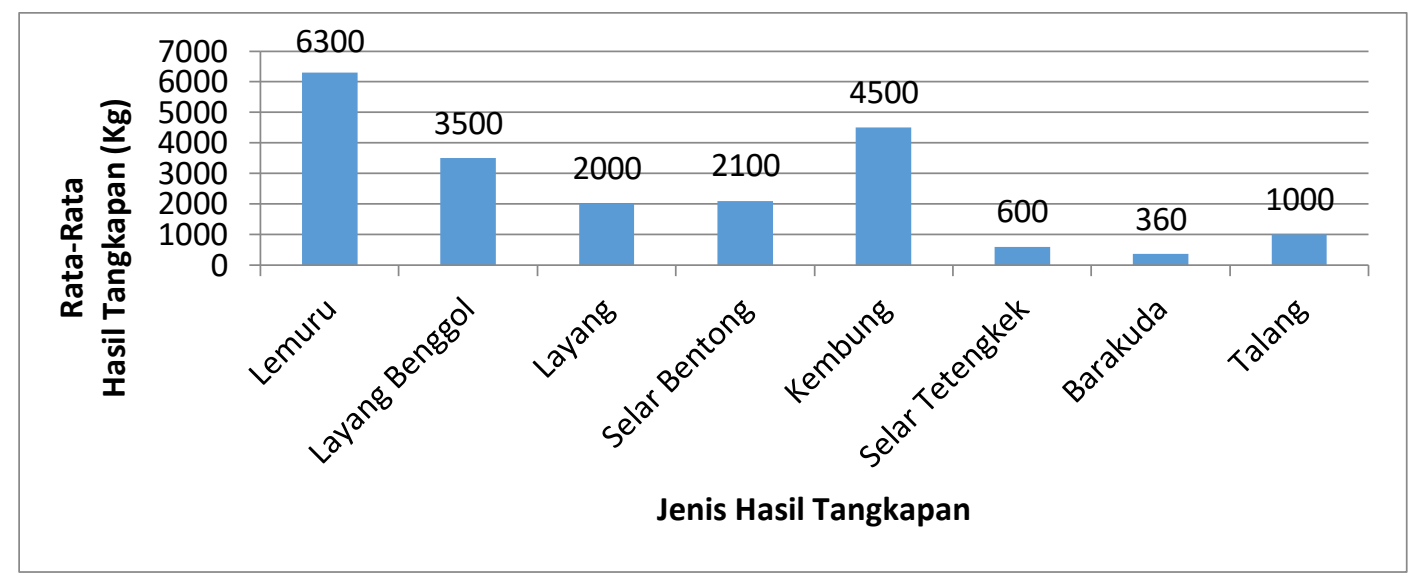

Gambar 28. Hasil Tangkapan Bulan April

\section{Pencucian Ikan}

Ikan dicuci menggunakan air laut bersih yang dialirkan melalui selang. Pencucian dilakukan dengan cara ikan disemprot menggunakan air laut sambil ikan digoyang-goyangkan hingga ikan bersih. Hal ini bertujuan membersihkan ikan dari sisik dan darah sebelum dibekukan. Kebersihan ikan juga berpengaruh terhadap harga jual ikan dipasaran karena jika ikan yang dipasarkan masih mengandung darah maka harga ikan tersebut akan menurun dari harga aslinya.

\section{Pendinginana Ikan/Pembekuan Ikan}

Ikan yang telah bersih kemudian disusun kedalam nampan berukuran $50 \times 30 \times 10 \mathrm{~cm}(10 \mathrm{~kg})$. Setelah itu nampan dimasukan kedalam freezer dan disusun pada rak-rak berupa pipa evaporator (18-24 jam). Untuk jenis ikan besar, penyusunan dilakukan dengan cara menggantungnya menggunakan besi berbentuk S pada dinding freezer. Lama pembekuan ikan tergantung dari cepat lambatnya penurunan suhu freezer. Ikan diketahui telah beku/siap dikemas jika suhu freezer berkisar antara $-25^{\circ} \mathrm{C}$ hingga $-26^{\circ} \mathrm{C}$.

\section{Pengemasan}

Pengemasan dilakukan menggunakan plastik berukuran $80 \times 50$ cm berbahan dasar LDPE (Low Density Polyethylene). Ikan yang telah dibekukan kemudian dikeluarkan dari dalam freezer untuk dikemas. Ikan beku pada nampan dilepaskan lalu dimasukkan kedalam plastik. Sedangkan Ikan yang berukuran besar langsung dimasukkan kedalam palka. Dalam pengemasan, terdapat penandaan pada ikatan plastik agar mudah membedakan jenis ikan. Ikan layang di tandai dengan tali rafia warna hitam, ikan layang benggol dan jenis lainnya ditandai dengan ikatan plastik langsung. Tali hanya digunakan pada kemasan iakan layang saja karena jenis ikan ini agak sulit dibedakan dengan layang benggol ketika beku. Sedangkan pada jenis ikan lainnya, kemasan plastik diikat secara langsung karena mudah untuk membedakannya. Hal ini bertujuan untuk memperlancar/mempercepat dalam bekerja.

\section{Penyimpanan}

Ikan yang telah dikemas langsung dimasukan ke dalam palka dan disusun. Penyusunan ikan dilakukan secara bertumpuk dimulai dari dasar palka hingga penuh. Untuk jenis ikan berekonomis tinggi, palka yang digunakan terpisah dengan ikan berekonomis rendah agar memudahkan pada saat pembongkaran atau pendistribusian. Suhu palka saat penyimpanan dijaga pada kisaran $-20^{\circ} \mathrm{C}$. Palka pada KMN. Samudera Windu Barokah terbuat dari fiber dan dibuat kedap udara, kedap air, dan diberi 
insulasi panas. Masing-masing palka berjumlah 9 ruang dan setiap palka dibuat secara terpisah antara satu dengan yang lain. Sedangkan untuk freezer terdapat 2 ruangan sebagai tempat memasak/ membekukan ikan hasil tangkapan. Kapasitas penyimpanan setiap palka mencapai 4,5-9 ton.

Palka dilengkapi dengan adanya pipa-pipa pendingin (pipa evaporator) yang dibuat menyambung dari satu palka ke palka yang lain dengan tujuan untuk menyalurkan udara dingin/refrigrant dari mesin pendingin ke dalam palka. Setelah udara dingin memenuhi dan mampu menjaga suhu ikan agar tetap dingin. Cairan yang terdapat didalam pipa-pipa tersebut adalah freon R22. Refrirgant berfungsi menyerap panas dari ikan atau ruangan yang direfrigerasi. Uap freon yang digunakan tidak berpengaruh dan tidak mengubah rasa, warna, atau tekstur dari ikan.

\section{Pembongkaran/Pendistribusian Ikan}

Hasil tangkapan yang telah ditampung/disimpan pada palka kemudian didistribusikan ke darat untuk dijual. Adapun pendistrbusian ini dilakukan dengan 2 cara yaitu dengan menggunakan kapal penampung sebagai sarana pengangkut ikan dari laut ke darat ataupun secara langsung membongkarnya di pelabuhan Tempat Pelelangan Ikan (TPI).

\section{Distribusi di Laut}

Pendistribusian yang dilakukan dengan menggunakan kapal Pengangkut atau Penampung yang dirancang khusus sebagai kapal pengangkut ikan dari kapal penangkapan ke TPI. Terdapat 1 Kapal penampung yang dimiliki PT. Widya Waksita Wijaya yang bertugas mengangkut/mengambil ikan hasil tangkpan dari kapal operasi KMN. Samudera Windu Barokah maupun kapal-kapal lain yang tergabung dalam PT. Widya Waksita Wijaya. Ikan yang di ambil akan dibawah ke TPI Juwana untuk dipasarkan. Pendistribusian ikan melalui kapal penampung dilakukan sebanyak 4 kali dengan rata-rata sebanyak 20 ton/pengangkutan. Secara keseluruhan jumlah ikan yang dikirim sebanyak 80 ton. Kapal penampung biasanya datang kurang lebih setiap 1 bulan sekali untuk mengangkut ikan sambil membawa perbekalan konsumsi dan operasional yang dibutuhkan kapal.

Puncak tertinggi pengiriman ikan terjadi pada bulan November hingga awal Desember. Ini terjadi karena banyaknya ikan yang tertangkap pada bulan tersebut. Sedangkan pada akhir bulan Desember hingga Januari terjadi penurunan yang cukup signifikan disebabkan oleh berkurangnya hasil tangkapan karena terjadi musim barat. Musim barat pada laut Jawa berlangsung mulai dari akhir bulan Desember hingga bulan Februari yang menyebabkan gelombang besar, akibat dari curah hujan tinggi dan angin yang kencang. Data menunjukan terjadi kenaikan pada bulan Januari dan februari bukan disebabkan oleh jumlah hasil tangkapan yang banyak pada bulan tersebut melainkan ikan yang dikirim merupakan hasil tangkapan yang sebelumnya disimpan/ditampung pada bulan November hingga Desember.

\section{Distribusi di Darat}

Pendaratan ikan dilakukan pada Pelabuhan Perikanan Pantai Bajomulyo unit II yang merupakan tempat/pangkalan pelelangan ikan. Ikan yang didaratkan berjumlah 91 Ton terdiri atas ikan Tongkol, Bawal Hitam, Layang Benggol serta Kembung. Pembongkaran dilakukan dengan cepat agar menjaga ikan tetap beku. Ikan yang telah dilelang kemudian didistribusikan ke sekitaran pulau Jawa.

\section{KESIMPULAN}

Teknik pengoperasian alat tangkap yaitu sama seperti purse seine light fishing pada umumnya yang menggunakan bantuan cahaya lampu untuk mengumpulkan gerombolan ikan 
selanjutnya ikan dialihkan pada lampu bangkra, lalu kapal bergerak melingkari bangkra sambil menurunkan alat tangkap kemudian diikuti dengan pengerutan bagian bawah jaring sehingga ikan terkurung didalamnya.

Hasil tangkapan total berjumlah $91403 \mathrm{Kg}$. Terdiri dari Kembung 22528 Kg, Selar Bentong $10283 \mathrm{Kg}$, Bawal Hitam $2791 \mathrm{Kg}$, Layang $9660 \mathrm{Kg}$, Tongkol $3371 \mathrm{Kg}$, Layang Benggol $12331 \mathrm{Kg}$, Lemuru 25160 Kg, Sulih 143 $\mathrm{Kg}$, Kuro $61 \mathrm{Kg}$, Layur $66 \mathrm{Kg}$, Selar Tetengkek 1362 Kg, Juwi 60 Kg, Kurisi $477 \mathrm{Kg}$, Kuwe $185 \mathrm{Kg}$, Barakuda 368 Kg, Selar $557 \mathrm{Kg}$, dan Talang $1990 \mathrm{Kg}$. Berdasarkan kategorinya didominasi Hasil Tangkapan Utama. Secara total ikan yang dominan adalah ikan Lemuru dengan jumlah $25160 \mathrm{Kg}$.

\section{DAFTAR PUSTAKA}

Ardidjha. 2007. Kapal Penangkapan Ikan. Sekolah Tinggi Perikanan, Teknologi Penangkapan Ikan. Jakarta.

Atmaja, S.B. 1999. Paparan Sunda. Variasi Geografi Hasil Tangkapan Layang (Decapterus spp).

Ayodhyoa. 1981. Teknik Penangkapan Ikan. Bogor : Yayasan Dewi Sri.

Junianto. 2003. Teknik Penanganan Ikan. Penebar Swadaya. Bandung

Mudztahid A. 2011. Metode Penangkapan dan Alat Tangkap Pukat Cincin (Purse seine). Tegal : Teknika Kapal Pengkapan Ikan.

Mulyanto. 1995. Dasar-dasar Pengelolaan Sumber Daya Perairan. Sekolah Tinggi Perikanan Jakarta.
Nazir, Moh. 2002. Metode Analisis Deskriptif, Penerbit Erlangga Januari 2002, Yogyakarta.

Sadhori. 1984 . Teknik Penangkapan Ikan. Bandung : Angkasa.

Santoso H, Bawole F. 2014. Teknik Pengoperasian Alat Tangkap Purse Seine pada Kapal Timur Laut 00. Bitung : Akademi Perikanan Bitung.

Sari NW. 2011. Purse Seine atau Pukat Cincin. Jawa Barat : Gudang Ilmu.

Subani W, Barus HR. 1989. Alat Penangkapan Ikan dan Udang Laut di Indonesia. Jakarta : Balai Penelitian Perikanan Laut.

Sudirman, Mallawa A. 2004. Teknik Penangkapan Ikan. Jakarta : Rineka Cipta.

Sukandarrumidi. 2004. Metedologi Penelitian : Petunjuk Praktis Untuk Penelitian Pemula. Yokyakarta

Usemahu AR, Tomasila L. 2003. Teknik Penangkapan Ikan. Jakarta : Departemen Kelautan dan Perikanan.

Vebronius Tani, Rasdam, Irandha C M Siahaan 2020. Teknik Penanganan Ikan Hasil Tangkapan di Atas Kapal Purse Seine Pada KM. Asia Jaya 03 Juwana Pati Jawa Tengah. Kupang : Jurnal Ilmu-ilmu Perikanan Dan Budidaya Perikanan

Wiyono, S. 2006. Menangkap Ikan Menggunakan Cahaya. Artikel IPTEK - Bidang Biologi, Pangan dan Kesehatan. 